\title{
Community Networking and Public Benefits
}

\author{
Arthur Cordell \\ Industry Canada / Mass Communication, Carleton University < Cordell.Arthur@ic.gc.ca $>$ \\ Paula A.Romanow \\ Mass Communication, Carleton University $<$ paularomanow@ns.sympatico.ca $>$
}

\begin{abstract}
In general, healthy networks seem to result in improved community welfare i.e., they are characteristic of public benefits. The converse is true of unhealthy networks. This paper explores if healthy networks are where limited government funding should be focused in order to get the greatest social payback, or if these funds should be spent helping to improve the strength of less healthy networks and communities, in order to improve the well-being of the country as a whole. It will do so by examining if community networks, both virtual and place-based, create public benefits on both the macro and micro levels.
\end{abstract}

\section{Introduction}

Everywhere one turns today, one is bombarded with talk of community, and networks, and computers, and often all three things at once. From the first glimmerings of the economic potential inherent in the new information and communication technologies (ICTs), the rhetoric from governments, academics, business, and community economic development (CED) organizations has held that if a community has access to and uses ICTs, then economic well-being is sure to follow. However, as experience has shown, this is not necessarily the case. For while ICTs do hold a great potential for immense positive benefits, not just in economic terms, but in broader applications for creating community networks to deal with civic engagement, education, health and other social services, as well as overall general knowledge and connectivity, they are tools, and the potential lies in how they are used, not their mere presence.

However, if government is going to fund community networks, it is important to identify which of these networks are more likely to generate positive externalities (that whole range of benefits from the somewhat tangible to the quite intangible such as community self-worth); these externalities are often referred to as social capital, and it is in this special sense that "public benefit1" aspects are attributed to

1 This article was initially entitled "Community Networks and the Public Good." However, the authors felt that the term "public good" is too limiting to this exploration, since it has a very specific definition in economics, to whit "...goods that may be enjoyed by any number of people without affecting other peoples' enjoyment" (www.ecosystemvaluation.org/glossary.htm). Or alternately, "a good which can only be supplied to all if it is supplied to one and the availability of which is not diminished by any one consumer's use of it" (www.chass.utoronto.ca/ reak/eco100/glosslist.htm). For example, an aesthetic view is a pure public good. No matter how many people enjoy the view, others can also enjoy it. This paper however, will keep separate the discussion of classical public goods and public benefits 
community networks. Some community networks are healthy ${ }^{2}$ i.e., they generate lots of external or social benefits. Some are less healthy, i.e., they generate few or no external benefits. In fact, unhealthy networks might be found to generate external or social costs, (e.g., putting or keeping in place undemocratic ways of governing).

In general, it seems evident that healthy networks result in improved community welfare. They have more of a "public benefit" characteristic. The converse is true with unhealthy networks. Therefore, is it towards healthy networks that limited government funding should be focused in order to get the greatest social payback? Or should these funds be spent helping to improve the strength of less healthy networks and communities, in order to improve the well-being of the country as a whole? This paper sets out to try and answer these questions by exploring whether or not community networks, both virtual and place-based, create public benefits on both the macro and micro levels. For if government can distinguish between healthy and unhealthy network investment situations, then there is the possibility for wiser spending on the part of government and increased welfare for the general community.

In an attempt to facilitate this decision-making process, this article will set out to determine which investment decisions are likely to yield the greatest benefits. It will do so by, first of all, ascertaining to what extent the concept of "public benefit" arising from community networks has been addressed to date; this will take the shape of an exploration of the concept of social capital, followed by a discussion of whether or not ICTs help to generate positive social ties. Secondly, drawing upon the existing literature, the paper will attempt to create a "taxonomy of public benefits" by identifying both tangible and intangible indicators of both healthy and less healthy community networks. Finally, we offer some recommendations for funding models that will ensure that the public goods aspects of community networks are optimized.

This sounds simple enough, but there are a number of issues that come to light when one starts to delve beneath the apparently obvious concepts of healthy and less-healthy communities. For instance, what exactly is a community? Is it a place-based geographical entity? A group that comes together to share similar interests? A group which engages in similar practices and beliefs? Individuals who never actually meet in person, but only interact in cyberspace? Or indeed, all of the above?

Further, what is a useful definition of community network? For the purposes of funding, should community networks be solely defined by technology? What about other types of networks found within communities such as those of kinship, friendship, business associates, religion, practice, shared interests, education and so on? For a community, no matter how it is defined, is made up of an immense number of networks, a multi-dimensional series of interconnections between people, organizations, macro-entities such as government and global corporations, and indeed the technologies with which all of these things interact.

It is, of course, of prime importance that these networks function in such a way as to create wellbeing in a community, i.e., that they generate social capital. It seems easy at first glance to see if a community is functioning in such a way as to provide the greatest possible set of public benefits to its members; is there a feeling of civic pride, community cohesion, sustainability, etc.? But sometimes

(although in many ways, it might be noted that creating a public good might in itself be one of the parameters indicating a healthy network). For our purposes here, however, although closely related to public goods, a public benefit is a somewhat looser concept, which we are defining as "something accessible to all members of a community, which has a healthy or good effect on the community as a whole."

2 The authors realize that the terms "healthy" and "unhealthy" come with a whole set of value-laden inferences. However, no other terms seem to accurately capture the idea of fully functioning networks that operate for the public benefit. For instance, a specific network may be totally functional, yet not operate in the best interests of the larger community as a whole e.g., the drug trade. Or a given community could also be said to be resilient, in the sense of long-lasting and self-sustaining, but this doesn't necessarily indicate well-being, e.g., generations who have lived on social assistance. And so we are using the term healthy in the biological sense, i.e., showing full strength and vigor, and free from any signs of disease. 
what appears on the surface to be working well, may in fact harbour deep-rooted problems. So what indicators can be used to tangibly measure what is often intangible? How to measure the unmeasurable? Further, how exactly do we determine what is beneficial? What may be of great public benefit to one community may well be of no public benefit to another. Therefore, is it possible to extrapolate any given set of indicators across all cases? And how do we fit ICTs into this discussion of what exactly constitutes public benefits?

All of these questions are of prime importance to government because it is their job to allocate a finite number of resources in such a way as to provide the largest number of benefits to the greatest number of citizens. But what if funding could be "fine-tuned?" What if funding could be allocated so that it is targeted at those communities where there is a greater potential for social benefits? Either the community in question possesses such characteristics already, or the creation of a community network is likely to create social benefits. Such knowledge would lead to "smarter" funding. Thus, having a sense of such indicators would benefit not just government, but also those communities in search of funding. Before considering just what these indicators might be, however, it is important to first explore the concepts of social capital, and community.

\section{The Role of Social Capital in Determining Public Benefits}

Social capital, which Putnam (2000) defines as "social networks and the trust and reciprocity that arise from them" (p. 19), is increasingly being understood as perhaps the most significant factor in determining a community's resilience. Indeed, Australian social commentator Eva Cox suggests that "Social capital should be the pre-eminent and most valued form of any capital as it provides the basis on which we build a truly civil society. Without our social bases we cannot be fully human. Social capital is as vital as language for human society" (in Cavaye, 2004, p. 2).

As Alejandro Portes (1998) points out, social capital is a term imported from the sociological literature into everyday language. In the process, however, it has "evolved into something of a cure-all for the maladies affecting society at home and abroad...[and] the point is approaching at which social capital comes to be applied to so many events and in so many different contexts as to lose any distinct meaning" (p. 2). Portes traces the term social capital to Pierre Bourdieu ${ }^{3}$, who briefly discussed the concept first in 1980, and then at more length in his chapter "The Forms of Capital", which appeared in a 1985 text on the sociology of education. Bourdieu's definition of social capital is more detailed than the more generally used one by Putnam seen above; Bourdieu suggests that it is "the aggregate of the actual or potential resources which are linked to possession of a durable network of more or less institutionalized relationships of mutual acquaintance or recognition" (in Portes, 1998, p. 3). This definition goes one step beyond Putnam's in that it emphasizes the quality and quantity of the resources, e.g., trust and reciprocity, that arise from social networks. Bourdieu also stresses the inherently economic outcomes of social interactions, and indeed, of all forms of capital, although he acknowledges that the processes that create various forms of capital do not necessarily arise from an economic base. Indeed, Bourdieu considers these processes to be the opposite of market exchanges in that they tend to lack clarity and well-defined time-lines, and the reciprocal obligations inherent in them are usually unspecified and have the potential to be violated. However Bourdieu's discussion makes plain how easily the idea of social capital could be adopted by business and government and translated into purely economic terms.

As Portes shows, economists such as Loury, Coleman, and Ben-Porath (in Portes, 1998), did indeed adopt the idea of social capital and develop its connections with other kinds of capital from an economic basis rather than a sociological one. Nonetheless, unlike financial or physical capital, social

3 However, Portes also acknowledges that the concepts underlying social capital, i.e., involvement in groups and the benefits of such involvement, are as old as sociology itself, and can be traced back to Durkheim and Marx. 
capital has been both interpreted and applied in a wide variety of situations. ${ }^{4}$ Portes, in his extensive review of the literature, identifies three basic functions of social capital: 1 ) as a source of social control and rule enforcement; 2 ) as a source of family support; and 3 ) as a source of benefits through extrafamilial networks, which he suggests is by far the most common use, a finding supported by much of the community development literature (see, for example, Healy \& Hampshire, 2003; Odasz, n.d.; Onyx $\&$ Bullen, 2000; and of course, Putnam, 2000).

But virtually all of the literature surveyed for this paper agrees that there is no single, clear definition of social capital; one could even go so far as to say that this is one of its hallmarks. However, following Cavaye (2004) and others, social capital has the following general characteristics: participation in networks of various kinds (e.g., family, neighbourhood, friends, business), reciprocity, trust, social norms, a sense of the "commons", and pro-activity and cooperation. Further, Cavaye (2004, p. 4-5) lists the following established understandings of social capital:

- It consists of three related forms i.e., bonding (relations between relatively homogenous groups such as family), bridging (ties across heterogeneous groups such as friends and colleagues), and linking (ties across social strata and community members accessing resources and information beyond the community itself).

- It interacts with other forms of capital.

- Communities have large reserves of latent social capital, evidenced in times of crisis as the community comes together without question to solve problems (e.g., in the face of a natural disaster).

- It is both a means and an end, i.e., it can mediate both relationships and participation that can, in turn, lead to concrete outcomes; while at the same time the relationships and networks that mediate these actions become strengthened.

- It fundamentally involves values, and what is considered to be "good" social capital cannot help but be a value judgment.

- It must be considered in the larger community context.

- It is a public good that increases as people within a community "use" it and decreases if they don't $t^{5}$.

It is also important to note that we must be cautious in considering social capital as a panacea for all problems concerning community. While it is true that the more social capital a community has, the more resilient it is, it is not a given that this resilient community will function in a positive manner. For instance, strong social networks also may support things like racism, bigotry, chauvinism, or a culture of poverty, drugs and/or crime. In instances such as these, social capital may well serve to ostracize those trying to change the culture in any way. In the same way, it can support unjust power structures at the macro level, and bolster dysfunctional familial ties at the micro level. "Social capital can consist of not only trust but also mistrust; information transferred between people can also be misinformation; and unjust norms can be perpetuated.

Strong bonding social capital can reduce tolerance of outsiders, stifle innovation and disagreement, support unhealthy norms, and cause people to reject alternatives" (Cavaye, 2004, p. 5). As Onyx and Bullen (2000) demonstrate in their study of five Australian communities, both bonding and bridging forms of social capital are just as likely to have a negative impact on a community as a positive one, especially where issues of diversity are present. On the other hand, communities that have

4 Portes (1998) identifies, among others, school attrition and academic performance, children's intellectual development, sources of employment and occupational attainment, juvenile delinquency and its prevention, and immigrant and ethnic enterprise. To these might also be added such things as engagement in civil society, community economic development, rural vs. urban communal networks, and the effects of an aging population on such things as health and other social services, among others. 5 This latter characteristic is of primary interest to this paper, and will be discussed at more length below. 
strong linking social capital tend to be more outward-looking, and often more resilient in a positive and sustainable manner. Despite the body of literature that focuses on the "dark side" of social capital (e.g., Cohen \& Prusak, 2001; Portes, 1998; Portes \& Sensenbrenner, 1993; Uzzi, 1997), there is a tendency to consider social capital within a communitarian perspective, and it is in this sense that ICTs and social capital are discussed in this paper.

\section{The Role of ICTs in Developing Social Capital}

It would appear at first glance that ICTs, and especially the internet, being inherently about interconnections and networks, should support and facilitate social and communal networks. Indeed, until fairly recently, ICTs have been enthusiastically held up as generators of social capital. This is particularly true in the mainstream, non-academic literature, where the rhetoric often outstrips realworld experience, occasionally with worrying results ${ }^{6}$ (see, for instance, Odasz, n.d.; Association for Community Networking, n.d.; National Civic League, 2003). But it is also seen in the work of the socalled Cyberutopians, those academics such as Lévy (1997), Heim (1998) and De Kerckhove (1997) who claim that the internet has created new and better ways to communicate. Indeed, academic research has found some empirical support for this view. For instance, there is evidence that the internet enhances social networks at a distance, especially with friends and relatives, through the use of e-mail (see, e.g., Boneva, Kraut \& Frolich, 2001; Hampton \& Wellman, 2001; Haythornthwaite, 2001b; Kavanaugh \& Patterson, 2001; Kazmer \& Haythornthwaite, 2001; Wellman, Quan Hasse, Witte, \& Hampton, 2001).

Further, researchers studying wired communities such as Blacksburg, Virginia, and "Netville", a suburb of Toronto, also found that increased levels of civic involvement corresponded with higher internet usage (Hampton \& Wellman, 2001; Kavanaugh \& Patterson, 2001). Tied to this, and of particular interest to the question of whether or not funding communities to help them develop ICT networks is an efficient use of government resources, is the finding that existing connectivity levels off-line appear to increase the potential for positive on-line connectivity. For instance, Kavanaugh and Patterson (2001) note that the Blacksburg Electronic Village project may well have been as successful as it was because it was located in a place-based community where high levels of social interconnectivity already existed. They suggest that high levels of social capital may be a prerequisite condition for, rather than a result of, effective computer-mediated communication. Wellman, et al. (2001) also found that those who had frequent contact with others via the internet also had frequent contact with them off-line. Their survey of 39,211 visitors to the National Geographic Society website found that the internet supplemented the participants' face-to-face and telephone communication rather than either increasing or decreasing it. They also found that heavy internet use can be associated with increased civic engagement, but concluded that for the most part, this did not mean that people became more engaged. Rather, those already engaged are increasingly using the internet as another tool in their work.

6 For instance, recent newspaper articles have discussed the I-Neighbors project at the Massachusetts Institute of Technology (MIT). This project set up a neighborhood web-site which let participants establish an e-mail address list, post personal profiles and then connect to other residents of their suburban community with similar interests. Over three years, those who used the site came into contact with more new neighbors than those who didn't. Keith Hampton, the lead researcher on the project, noted that by meeting those with similar interests through the website, people formed more diverse social ties. However, he also found that these new on-line relationships typically lacked strength, and tended to be weaker social ties (The Internet makes good neighbors, 13 September, 2004; Who's knocking at your door?, 26 August, 2004). This type of connection is reminiscent of on-line dating services or other types of chat-rooms; where the potential for false, or at the least misleading, information being posted, has been well-documented. In general, it is easier to mislead others when no physical cues are present to help the receiver process the information being sent. Even telephone conversations provide verbal cues such as tone of voice, accents, etc. 
A number of other studies echo this finding. As Haythornthwaite puts it, "Connectivity seems to go to the connected, that is, greater social benefit from the internet accrues to those already well situated socially. As Nie (2001) pointed out, connectivity already goes to those with higher levels of income and education" (2001a, p. 376). In other words, those with strong social ties off-line were more likely to have strong ties on-line; the converse also appears to be true ${ }^{7}$. So it might well appear that an efficient allocation of funds for ICTs would be to support place-based communities that already show strong evidence of positive social capital.

The danger of this argument however, is that such a strategy can't help but to reinforce the socalled digital divide. According to Statistics Canada (2004), in 2003, 7.9 million ${ }^{8}$ Canadian households had at least one individual who used the internet regularly, an increase of $5 \%$ from $2002^{9}$; however, the same survey also showed that internet adoption was highest in households with higher income levels, those which had members in the workforce, and those which had higher levels of education. In contrast, in 2003, 3.6 million Canadian households had never used the internet, $49 \%$ of which were found in the lowest income group. As Haythornthwaite (2001a) points out, "Great though these numbers are, they indicate a large proportion of people who are not connected to the internet, do not know about it, have no interest in using it, have no affordable access to it, or have poor infrastructural support for it. The large social phenomenon of the internet is passing some by, and for better or worse, that sector is failing to gain access to the resources available to those with access to the internet" ( $p$. 366). Thus the question is, would government better serve the population as a whole by putting in place funding to help support initiatives that increase a community's positive social capital in ways that don't necessarily involve technology, before allocating funds specifically for ICT and connectivity projects?

The answer to this question may come, in part, from more critical consideration of the relationship between ICTs and social capital. One of the overall findings of this body of literature is that it is simply too early in the development of the internet to determine with any authority whether or not ICTs increase social ties in any lasting or meaningful way; in part, this is because of the way that research has positioned. A number of researchers are very explicit in their warning that setting one type of communication against another, i.e., face-to-face against computer-mediated, is counterproductive, especially as ICTs become more and more integrated into our everyday lives. Caroline Haythornthwaite (2001a, p. 363-378) perhaps says it best:

Much existing research on computer-mediated communication (CMC) and online behaviour has laid out differences between CMC and face-to-face communication and provided in-depth reports on online communities. Whereas important research has been done from this perspective, its concentration on CMC versus face-to-face, online versus offline, and virtual versus real has perpetuated a dichotomized view of human behaviour. These dichotomies pit one form of CMC against another ... as well as one category of human endeavour against another.... In considering the integration of the Internet into our daily lives, we also need to remember that, as many point out, the Internet is a new social phenomenon that has been in place for fewer than 11 years. We already see that experience and time online changes behaviour; we are watching an emerging phenomenon, not a mature one.

7 However, a number of studies also found that very high internet usage appears to contribute to higher rates of depression among individuals (e.g., Kraut, Lundmark, Kiesler, Mukhopadhyay \& Scherlis, (1998); LaRose, Eastin \& Gregg, 2001). Of particular concern is a case in Winnipeg concerning the death of a 53 year-old man. Because he had few social ties, suffered from a disability and so was rarely seen outside his apartment, and had all of his day-today banking deposits and withdrawals set up online, it was two years before anyone discovered his body (George, 2004). As George goes on to point out, "new technologies like electronic banking have created a system in which it's possible to become so physically disengaged from the day-to-day administration of your own affairs that your life can effectively go on without you, perhaps indefinitely" (2004, p. 32).

8 Of a total of 12.3 million households.

9 And substantially down from increases of $19 \%$ in 2000 and $24 \%$ in 2001 . These individuals accessed the internet at home, work, school and/or a public library or other location. 
Other researchers echo this caution. Pigg and Crank (2004), in their exploration of the functionality of various ICTs and resulting ties to social capital formation, conclude that "More research and further documentation is necessary before we can say for certain that ICTs can and do create social capital and, thereby, build community. Enhancing social networks is obviously necessary, but this analysis suggests it is certainly not sufficient to support the claim of ICT advocates" (p. 6970). Anderson \& Tracy (2001), Blanchard (2004), Huysman and Wulf (2004) and Kavanaugh \& Patterson, (2001) echo this sentiment. At the present time, it is safe to say that ICTs, as they are being assimilated into society, tend to be used as an adjunct to other older technologies, such as the telephone, and should be considered in this light.

\section{Community is as Community Does}

However, if the jury is still out on whether or not ICTs generate the social ties that constitute positive social capital, and vice versa, the same may not be said about computer-mediated community networks. Overwhelmingly, the literature suggests that where community networks exist, they prove beneficial to some extent (see, for instance, Casapulla, de Cindio \& Ripamonti, 2001; Day, 1997; Gurstein, 2001; Jones, 2003; London, 1997; Odasz, n.d.; Schuler, 1996; Silver, 2003). For the purposes of this article, community networks can be defined as "a network of computers with modems that allow users to connect to a central computer which provides community information and a means for the community to communicate electronically.... Unlike 'virtual communities' community networks are based in a physical place... The common element of users of community networks is their physical proximity and interest in local issues that affect them all” (Hall, n.d., $\{12$ ). In general, community networks have three characteristics that separate them from other forms of computer based communication:

1) They focus on local issues, culture, and ownership, as well as providing forums for community discussion and problem solving;

2) They strive to reach all groups and individuals in a community, stressing public access and computer skills acquisition (e.g., the Community Access Program in Canada, as well as the many freenets found in various cities) for not just the computer literate, but also marginalized groups and non-traditional users of technology; and

3) They emphasize democratic participation and community development.

To this might be added a fourth characteristic, if not of the network itself, then of the individuals who run it: they believe implicitly that "community networks can build and strengthen community identity and ties" (Hall, n.d., 927 ). This is borne out in some of the more common aims underlying the creation of most community networks: providing otherwise inaccessible services and information to the community, stimulating local economic development enterprises, providing training to marginalized groups, etc. The fundamental element of community networks, however, is that they are developed by the local people for the local people, with an understanding of just what the local needs are.

The question needs to be asked however, in determining whether or not such community networks provide public benefits, is exactly how they compare to other types of non-computer mediated community networks in this regard. This is because while place-based communities are still considered as the primary unit in terms of funding allocation, increasingly, there are other types of communities that may well be more suited to development in terms of ICTs, and perhaps it is these that may be more appropriate for funding.

What exactly constitutes a community has engendered a great deal of debate in the social sciences literature. The complexities inherent in the idea of community reach across almost all disciplines and theoretical variations (for some thorough reviews of the literature in this area, see Cohen, 1985; Connell, 2000, 2002; and Liepins, 2000). And just as academics struggle with the concept of community, so do governments. As noted above, this is a crucial question for governments, because how funding is allocated depends in many ways on determining the constitution of a community. A 
potentially useful breakdown of types of communities may be found in the New Zealand government's recent draft Digital Strategy. It suggests that "there are a number of ways of defining communities and together they make up the interconnected systems of society" (Government of New Zealand, 2004, p. 96 , emphasis added). Some of these approaches to community include: geographic communities; communities of interest such as those for business, research; hobbies, sports or politics; communities of identity or circumstance, such as youth, seniors or the physically or mentally challenged; non-profit and voluntary sectors, also known as the community sector; and ethnic and cultural communities. In Canada, however, as David Connell notes, while "references to community remain dominant in today's social policy" (2000, p.2), a hard and fast definition of what exactly is meant by community is absent. ${ }^{10}$

The one point of agreement seems to be that the root of community in the Latin communis, meaning common or shared, is a good place to start. As we saw in our discussion of social capital, the stronger the social ties, the more resilient the community. Place-based communities consist of a myriad of such ties, which perhaps can better be thought of as networks, although the idea of network is as rife with complexity as the idea of community.

There is a tendency to think of networks as hierarchical entities, a series of connections able to be delineated in a flow chart. This is too simplistic. For, while the root concept of the network is undoubtedly that of connections, rarely (outside perhaps of organizational theory) are these able to be defined hierarchically, or indeed linearly, because networks are also defined by their context. A rural community is a good illustration of this: depending on the context, the network of social relations is constantly shifting, thinning out in some places while deepening in others: a person is a farmer within a certain set of relationships, while at the same time being the mayor, or a parent or a spouse or a member of a church, etc. But not all members of the church are family, nor are all those involved in the public sphere necessarily farmers or involved in agriculture. Strong ties in some directions, weaker in others. The important notion here is context. In many ways, context is what defines a community's boundaries and needs to be considered in the allocation of funding.

A given community of the homeless for instance, may find the ability to access the internet much less useful than a community of tourism operators; on the other hand, another community of homeless may be able to upgrade literacy skills, or seek employment or health information with the help of ICTs. It depends on a number of things, such as familiarity with the technology, access, willingness to learn and even physical locale. Funding decisions must be made in a context-specific way, and from a bottom-up approach. Certainly, the individuals and groups requesting funding know what their needs are, and generally have a fairly good idea how they can best be met. ${ }^{11}$ And sometimes these needs aren't centred in a physical locale, e.g., groups that advocate for health-related issues, literacy, and other social justice matters. Funders need to consider communities in ways other than simple geography.

\section{Measuring the Unmeasurable: Indicators of Health in a Community}

As we mentioned above, determining the health and resilience of a community is not an easy task. One purpose of this paper, however, is to try to come up with a taxonomy of indicators that funding

10 When conducting research for his doctorate, Connell had "the opportunity to listen to a presentation by a senior, federal bureaucrat that included many references to community, e.g., community capacity. Following the presentation, [he] asked the presenter if community was defined for these policies. The presenter replied there was no definition" (2000, p. 2n).

11 For instance, the Canadian Research Alliance for Community Innovation and Networking's (CRACIN) case study sites have indicated that this is indeed the case. The implementation of ICT is helpful, but not necessarily the answer to all of their prayers. The authors have also heard, in the course of other community-based research, the frustration that arises when funding requests are met with a cookie-cutter approach by government. For while funders must of course be careful of risk, it can equally be said that without risk, nothing creative and positive can take place. 
agencies might use as guidelines when evaluating requests for funding. However, before embarking on this task, it is important to stress again that a cookie-cutter approach to resource allocation is not only counterproductive, but may well be harmful to the communities that governments wish to help. As Spigelman (2001) notes, "not everything that counts can be counted. Some measures can only be judged" (p. 2). He adds "Perhaps the most definitive characteristic of the 'new public management' is the greater salience that is given to what is called the 'three E's'-economy, efficiency and effectiveness-in competition with other values of government activity, such as accessibility, openness, fairness, impartiality, legitimacy, participation, honesty and rationality" (p. 3). We need to be reminded that quantitative measurement, whether funding formula or performance indicator, is as value-laden as more qualitative methods ${ }^{12}$ Again, every application must be taken on its own merit, and evaluated within its specific context. Thus, the following discussion is meant as a guideline and not as a checklist.

Over the last 20 years, there has been an increasing interest in being able to articulate indicators of civic well-being, arising mainly from decreasing resources for community support. Of particular use to this paper was the work done by Warren Dow, who has pulled together a review of many of the existing assessment resources both in Canada and around the world (Dow, 2003). It is impossible to outline all of them; the 96 pages of his report contain hundreds of annotated links and portal sites where assessment tools can be found. However, drawing on this work, as well as others, we shall attempt to outline a few of the most effective tools, ending with a list of what appears to be the most common and useful indicators in assessing community well-being ${ }^{13}$.

Healey and Hampshire discuss community well-being indicators in terms of community resilience, which they define as "the individual and collective capacity to respond to adversity and change" (2003, p. 1). They conducted a three year study of four geographically diverse communities in Australia to determine whether or not social networks do in fact contribute to community resilience, and what the implications of their findings might be for government policy. They found that personal resilience is an important factor in overall community resilience. Further, they list the following indicators (p. 4-9):

- A positive outlook on the future, arising from such things as a large supportive friendship network, feeling part of the local community, volunteering in local groups, the involvement of local businesses in the community, and a belief that government institutions seek to benefit the community ${ }^{14}$;

- The capacity to be proactive in the face of adversity; and

- The feeling among residents that "life is manageable", which arose from higher income levels, being older, and having large friendship and family networks.

12 This is backed up by a number of municipal studies into ICT use and their communities. For instance, the City of Seattle's Community Technology Program, in its report 2000-2001 Information Technology Indicators for a Healthy Community notes that “...there are areas where defining the indicator is extremely difficult or where there remain significant barriers to collecting reliable and valid information.... Statistical data doesn't always tell the whole story. There are qualitative measures that could be included or refined. For example, measuring culturally relevant content continues to be a challenge. Some issues and benefits are most relevant when told in stories...." (2002, p. vii).

13 Because of the community-specific nature of these, we will not attempt to draw up a definitive list of indicators, but rather show a sample of some studies and tools most applicable within the Canadian context; indeed, as Sharpe and Osberg (in Reed, 2000) correctly point out, the level of these indicators are less important than the trends they show. Further, because many of these assessment tools deal with specific areas of community such as health, aboriginal concerns, education and so on, we have concentrated on those tools which try to get an overall picture of a community. It goes without saying that should funders be looking in specific areas; then some of these other tools would be of more value; however, since the purpose of this article is to evaluate the overall public benefits arising from community networks, it makes more sense to look at some of the more general ones. 14 Interestingly, respondents felt that government involvement in the community was more beneficial than that of big business. 
However, in their conclusion, they note that different institutions are important to different communities, and stress that each must be looked at in context. This finding backed up by Stoll, et al. (2001), who note that the use of indicators can be helpful, but that each indicator must be considered in the overall context of the community in question.

One of the most well-known and widely used set of indicators can be found in the Oregon Benchmarks. They are described by Lewis and Lockhart (n.d.) as "simple, holistic, yet transparentOregon's approach to state-wide planning gets different sectors and interests tracking change in terms of a common set of specific outcomes. Having agreed on what they wish to achieve, people can turn to more constructive issues-what is effective and what is not" (p. 1). One of the most useful things about this process is its longitudinal study over 20 years, with a feedback loop that allows all levels of participants to learn as they go, and make adjustments accordingly. The Benchmarks themselves are drawn from the economic, social and environmental factors that Oregonians believe are most important to their quality of life, and fall under the following seven categories:

- Economy

- Education

- Civic engagement

- Social support

- Public safety

- Community development

- Environment.

Some of the specific indicators found within these categories are: employment dispersion (Economic); teen pregnancy rates Social support); and wetland preservation percentages (Environment).

In an Australian study, Pepperdine (2000) provides an in-depth discussion of indicator development. In it, she notes that the following key indicators of community well-being and successful functioning were derived directly from the community's residents:

- Political representation

- Sense of the future

- Maintenance of services and facilities

- Maintenance of population (numbers)

- Even age structure

- Sense of community of belonging

- Community-mindedness

- Neighbourliness

- Co-operation

- Accepting of difference

- Communication

- Community activities

- Availability of meeting places

- Active participation

- Presence of leaders and vibrant people

- Employment opportunities

- Economic viability

- Environmental issues.

Interestingly, she concludes that contrary to the traditional emphasis on economics as the underlying element of (in this case, rural) sustainability, her respondents identified indicators that highlighted social sustainability as more important, a key finding, one might think, for policy makers. (The experience of the Nova Scotian town of Canso, which has been continuously threatened with closure because of the failure of the local fishing catch, but whose local population is very actively resisting, appears to back up this finding.)

In his report on how researchers might best develop civic indicators in Canada, Paul Reed (2000) noted 100 potential civic indicators in 16 categories: 
- Economic resources

- Work

- Situation of children

- Situation of young people

- Situation of adults

- Families

- Population stability

- Destabilizing and social stress conditions

- Institutional resources and capacities

- Community physical facilities

- Environment

- Time use

- Civic participation

- Social participation

- Caring and contributing to the community

- Trust and confidence in institutions.

What is particularly evident from this set of indicators is the importance of the mix of both civic and personal features. Reed also notes that "the great majority of these projects [development of community indicators] are more output-oriented than input-oriented. Far more is known about 'where we are at' or 'where we want to go'-be they objectives for water quality, health care, educational attainment, economic development-than about the capacity and resources required to produce those results" $(2000$, p. 44). He also points out that while many Canadian and international publications outlining social indicators exist, few of these national level compendia have "developed a systematized or core methodology of the kind that could be disaggregated or easily replicated at the community level" (p. 45), which speaks again to the need for context at the community level.

There are a number of Quality of Life indices being used to measure community well-being, many of which came into being as government funding for social services began to erode. In general, these measure four things: social, health, economic and environmental well-being, and are used to track the perceived growth or decline of a community through determining the overall satisfaction among its residents. Of particular interest is the Federation of Canadian Municipalities' Quality of Life Reporting System (in Reed, 2000), which tracks nine areas and is one of the most comprehensive assessment tools used in urban Canada:

- Population resources

- Community affordability

- Quality of employment

- Quality of housing

- Community stress

- Health of community

- Community safety

- Community participation

- Strategic and sustainable well-being.

This particular assessment focuses on the effects of the downloading of public services from a national or provincial level to the municipal, and is one of the first to do so on a nation-wide basis.

Overall, what is evident from this brief survey is that while most of these tools are developed by various levels of governance, and are being used either to track social trends, or to conduct cost-benefit analyses of various funding projects and there is a mix of the personal and the private (especially from those developed with public consultation). And, strikingly, what appears to be most important to communities are close interpersonal relationships, rather than external environments, as the primary source of satisfaction. Thus it may well be that community networks, with the emphasis on social ties, may prove to be important as public benefits.

\section{Conclusions}


As we have seen, while community networks may well both be and produce public benefits, there is currently not enough data to state this with certainty. Further, the emphasis on social capital from a communitarian standpoint must be tempered with caution; it is not enough to say that by developing social capital, we are improving our communities. Finally, while having some guidelines for indicators of community well-being will be of benefit to funding agencies, there are so many contextual concerns that for the most part, such lists may prove detrimental to the very communities that funding agencies are trying to help.

Thus, we offer the following recommendations:

- Funding agencies should consider providing support for the development of strong linking types of social capital, as this is what appears to create the most resiliency within communities.

- When allocating funds for ICTs, the best results may be achieved when such funds are directed to those place-based communities that already show evidence of strong positive social capital; the development of computer-mediated networks in and of themselves will not necessarily generate community well-being because high levels of social capital may be a prerequisite condition for, rather than a result of, effective computer-mediated communication.

- Funding agencies might better serve their over-all population by supporting those initiatives that increase a community's positive social capital in ways that don't necessarily involve technology, before allocating funds specifically for ICT and connectivity projects. However, it should be recognized that there is a danger in funding only those place-based communities that already exhibit strong positive social capital, as this may serve to strengthen the so-called digital divide.

- Funding agencies should pay particular attention to individual community context. To this end, attention should be paid to the needs of individual local applications, rather than applying a one size fits all approach.

- Place-based communities are not necessarily ideal for investing the bulk of funds for ICT for development. Other types of communities might benefit more from ICT use, especially online or virtual communities.

It appears evident that adding ICT to a community characterized by strong social cohesion (a healthy community) will enhance the social infrastructure of the community and add to the public good. It is equally clear that where the community is unhealthy, i.e., where there is little social cohesion, it is unlikely that the addition of ICT will bring about a change in the community-and thus, few public good benefits can be expected to be realized.

The authors thus conclude that incremental investments in ICT in communities should be targeted at those communities that are likely to benefit, that is those communities which are most likely to use the technology to enhance the public good. The ICT investments that would have gone into unhealthy communities should be re-directed directly into the community itself. By targeting investments, we are not abandoning those communities with low social cohesion. Rather we are saying that scarce resources should be directed where the pay-offs are greatest. Putting ICT into unhealthy communities, i.e., communities with low social cohesion, is not a good use of public funds.

\section{References}

Anderson, B., \& Tracey, K. (2001). Digital living: The impact (or otherwise) of the internet on everyday life. American Behavioral Scientist, 45(3), 456-475.

Association for Community Networking Website (n.d.). About AFCN. Retrieved September 8, 2004 from http://www.afcn.org 
Blanchard, A. (2004). The effects of dispersed virtual communities on face-to-face social capital. In M. Huysman \& V. Wulf (Eds.), Social capital and information technology. (pp. 53-74). Cambridge, MA: MIT Press.

Boneva, B., Kraut, R. \& Frohlich, D. (2001). Using e-mail for personal relationships: The difference gender makes. American Behavioral Scientist, 45(3), 530-548.

Casapulla, G., de Cindio, F., \& Ripamonti, L. A. (2001). Community networks and access for all in the era of the free Internet: 'Discovering the treasure' of community. In L. Keeble \& B. Loader (Eds.), Community informatics: Shaping computer-mediated social relations (pp.89-100). London: Routledge.

Cavaye, J. (2004). Social capital: A commentary on issues, understanding and measurement. PASCAL Observatory. Retrieved June 12, 2004 from http://www.obspascal.com/reports/2004/Cavaye.html

City of Seattle. (2002). 2000-2001 information technology indicators for a healthy community. Seattle: City of Seattle Information Technology Indicators Project.

Cohen, A. (1985). The symbolic construction of community. London: Tavistock.

Cohen, D., \& Prusak, L. (2001). In good company: How social capital makes organizations work. Boston, MA: Harvard Business School Press.

Connell, D. (2001). Re-formulating community as a complex social system. [Qualifying Exam Paper]. Guelph: University of Guelph.

Connell, D. (2002, August). Community: A place between risk and security. Paper presented at the Rural Sociological Society 65th Annual Meeting: The Community Effect in Rural Places, Chicago, IL.

Day, P. (1997). The community benefits of electronic networking. Retrieved May 3, 2004 from

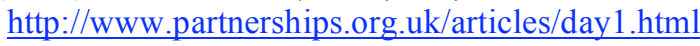

De Kerckhove, D. (1997). Connected intelligence: The arrival of the web society. Toronto: Somerville House.

Dow, W. (2003). Sources and resources for community information development. Ottawa/Port Alberni, BC: The Centre for Applied Social Research / The Canadian Centre for Community Development.

Federation of Canadian Municipalities. (1999). Quality of life reporting system. Retrieved September 8, 2004 from http://www.fcm.ca/qol3/team3.htm

George, L. (2004, Sept. 20). A high tech ghost story. Maclean's Magazine.

Government of New Zealand. (2004). Digital strategy: A draft New Zealand digital strategy for consultation. Retrieved July 12, 2004 from http://www.med.govt.nz/pbt/infotech/digitalstrategy/draft/draft.pdf

Gurstein, M. (2001). Community informatics, community networks and strategies for flexible networking. In L. Keeble \& B. Loader (Eds.), Community informatics: Shaping computermediated social relations (pp.263-283). London: Routledge.

Hall, S. (n.d.). Community networks - community development through information technology. The Online Planning Journal. Retrieved September 7, 2004 from http://www.casa.ucl.ac.uk/planning/articles $11 / \mathrm{cn} . \mathrm{htm}$

Hampton, K., \& Wellman, B. (2001). Netville online and offline: Observing and surveying a wired suburb. American Behavioral Scientist, 43(3), 475-492.

Haythornthwaite, C. (2001a). The internet in everyday life. American Behavioral Scientist, 45(3), 363382. 
Haythornthwaite, C. (2001b). Tie strength and the impact of new media. In Proceedings of the 34th Hawaii International Conference on System Sciences, Maui, Hawaii (p.1019). Washington, DC: IEEE Computer Society.

Healy, K., \& Hampshire, A. (2003, July). The "rediscovery" of community in Australian social policy. Paper presented at the Social Policy Research Centre Conference, 9 July, 2003, in Sydney, Australia. Retrieved July 9, 2004 from http://www.bensoc.asn.au/research/sprc_2003.html

Heim, M. (1998). Virtual realism. Oxford: Oxford University Press.

Huysman, M. \& Wulf, V. (2004). Social capital and information technology: Current debates and research. In M. Huysman \& V. Wulf (Eds.), Social capital and information technology (pp. 116). Cambridge, MA: MIT Press.

Jones, M. (2003). Can technology transform? Experimenting with wired communities. In B. Kolko (Ed.), Virtual publics: Policy and community in an electronic age (pp.354-384). New York: Columbia University Press.

Kazmer, M. M., \& Haythornthwaite, C. (2001). Juggling social worlds: Distance students online and offline. American Behavioral Scientist, 45(3), 510-529.

Kavanaugh, A., \& Patterson, S. (2001). The impact of community computer networks on social capital and community involvement. American Behavioral Scientist, 45(3), 496-509.

Kraut, R. P., Lundmark, V., Kiesler, S., Mykhopadhyay, T., \& Scherlis, W. (1998). Internet paradox: A social technology that reduces social involvement and psychological well-being? American Psychologyist, 53(9), 1017-1031.

LaRose, R. Eastin, M. S., \& Gregg, J. (2001). Reformulating the Internet paradox: Social cognitive explanations of Internet use and depression. Journal of Online Behavior, 1(2). Retrieved September 8, 2004 from http://www.behavior.net/JOB/v1n2/paradox.html

Lévy, P. (1997). Collective intelligence: Mankind's emerging world in cyberspace. (R. Bononno, Trans.). New York: Plenum Press.

Lewis, M., \& Lockhart, S. (n.d.). The Oregon Benchmarks: Oregonians are getting results from this approach to governance. Can we in BC? Retrieved 13 May, 2004 from http://www.cedworks.com/files/pdf/papers/OBM_main.pdf

Liepins, R. (2000). New energies for an old idea: reworking approaches to 'community' in contemporary rural studies. Journal of Rural Studies, 16, 23-25.

London, S. (1997). Civic networks: Building community on the net. Paper prepared for the Kettering Foundation. Retrieved July 9, 2004 from http://www.scottlondong.com/reports/networks.htm19

National Civic League. (2003). Bridging the gap between citizens and local government with information technology: Concepts and case studies. Denver, CO: National Civic League.

Odasz, F. (n.d.) Community networking: Leveraging the public good electronically! Retrieved April 10, 2004 from http://lone-eagles.com/articles/networking.htm

Odasz, F. (n.d.). Realizing cultural and community sustainability through internet innovations in Alaskan native villages. Retrieved April 10, 2004 from http://lone-eagles.com/villagesustainability.htm

Onyx, J., \& Bullen, P. (2000). Measuring social capital in five communities. The Journal of Applied Behavioral Science, 36(1), 23-42.

Pepperdine, S. (2000, June). Social indicators of rural community sustainability: An example from the Woady Yaloak Catchment. Paper presented at the First National Conference on the Future of Australia's Country Towns, Bendigo, Australia, 29 June, 2000. Retrieved July 9, 2004 from http://www.regional.org.au/countrytowns/strategies/pepperdine.htm 
Pigg, K., \& Crank. L. (2004) Building community social capital: The potential and promise of information and communications technologies. The Journal of Community Informatics, 1(1), $58-73$.

Portes, A. (1998). Social capital: Its origins and applications in modern sociology. Annual Review of Sociology, 24(1), 1-24.

Portes, A., \& Sensenbrenner, J. (1993). Embeddedness and immigration: Notes on the social determinants of economic action. American Journal of Sociology, 98, 1320-1350.

Putnam, R. (2000). Bowling alone: The collapse and revival of American community. New York: Simon \& Shuster.

Reed, P. (2000). Developing civic indicators and community accounting in Canada. [draft]. Ottawa: Statistics Canada / Carleton University.

Schuler, D. (1996). New community networks: Wired for change. Reading, MA: Addison-Wesley Publishing Company.

Silver, D. (2003). Communication, community, consumption: An ethnographic exploration of an online city. In B. Kolko (Ed.), Virtual publics: Policy and community in an electronic age (pp. 327-353). New York: Columbia University Press.

Spigelman, J. J. (2001, November). Quality in an age of measurement: The limitations of performance indicators. Lecture presented to the Sydney Leadership Alumni, Sydney, Australia on November 28, 2001.

Statistics Canada. (2004, July 8). Household internet use survey. Retrieved October 1, 2004 from http://www.statcan.ca/Daily/English/040708/d040708a.htm

Stoll, K., Chasquinet, F., Menjou, M., Camacho, K., Acesso, F., \& Khellady, Y. (2001). Learning about ICT's role in development: A framework toward a participatory, transparent and continuous process. Ottawa: IRDC.

The internet makes good neighbours, according to a recent study. (2004, September 13). The Toronto Star. Retrieved 15 September, 2004 from CRACIN-discussion listserve.

Uzzi, B. (1997). Social structure and competition in interfirm networks: The paradox of embeddedness. Administrative Science Quarterly, 42, 35-67.

Wellman, B., Quan Hasse, A., Witte, J., \& Hampton, K. (2001). Does the internet increase, decrease, or supplement social capital? Social networks, participation, and community commitment. American Behavioral Scientist, 45(3), 436-455.

Who's knocking at the door? Check your e-mail first. (2004, August 26). The New York Times. Retrieved 12 September, 2004 from CRACIN-discussion listserve 